This item was submitted to Loughborough's Research Repository by the author.

Items in Figshare are protected by copyright, with all rights reserved, unless otherwise indicated.

\title{
Integrated solutions for total asset management through "RIVANS"
}

PLEASE CITE THE PUBLISHED VERSION

http://dx.doi.org/10.1108/BEPAM-07-2015-0034

PUBLISHER

(c) Emerald

VERSION

AM (Accepted Manuscript)

\section{PUBLISHER STATEMENT}

This work is made available according to the conditions of the Creative Commons Attribution-NonCommercialNoDerivatives 4.0 International (CC BY-NC-ND 4.0) licence. Full details of this licence are available at: https://creativecommons.org/licenses/by-nc-nd/4.0/

\section{LICENCE}

CC BY-NC-ND 4.0

\section{REPOSITORY RECORD}

Smyth, Hedley J., Aaron Anvuur, and Illona Kusuma. 2019. "Integrated Solutions for Total Asset Management Through "RIVANS"”. figshare. https://hdl.handle.net/2134/24690. 


\title{
Integrated solutions for total asset management through
}

\section{"RIVANS"}

Hedley Smyth, Aaron Anvuur and Illona Kusuma

\begin{abstract}
Purpose: Examine the extent of integration in delivering value from design and construction (DC) activities for total asset management (TAM) and operations post-completion. DC and operations and management $(\mathrm{OM})$ are both addressed. The problem owners are those in roles and organisations responsible for integrating $\mathrm{DC}$ with $\mathrm{OM}$. The goal is to show the extent of integration between actors along the project lifecycle. Relationally integrated value networks (RIVANS) provide the conceptual lens for the analysis.
\end{abstract}

Design/methodology/approach: A mixed method approach was used. A questionnaire survey and semi-structured interviews were employed.

Findings: There is a lack of engagement between DC and OM. The trend is moving counter to integration. BIM is not found to be a technical solution.

Research limitations/implications: The mixed method helps extend the RIVANS perspective. Further research to understand and support integration is needed, especially qualitative research to provide greater granular understanding.

Practical implications: The identified trend away from integration poses management challenges in delivery and for sustainability in use. Supply chains engage specialists, yet internal and interorganisational collaboration require management attention to value creation. This includes the DC-OM interface. Both sides can benefit from increased engagement.

Social implications: Infrastructure and property provision will continue to fall short of user and environmental functionality without improved integration. 
Originality/value: A contribution to the project and asset management interface is made, showing low integration, disengaged asset management. BIM is unable to plug the gaps. The RIVANS analytical lens provides a perspective for improvement.

Keywords: BIM, collaboration, facilities management, integration, networks, relationally integrated value networks, RIVANS, total asset management

Classification: Research paper

\section{$1.0 \quad$ Introduction}

Integration and value optimisation have been studied through design and in construction and supply chains (e.g. Kumaraswamy et al., 2002; Dubois and Gadde, 2000; Bresnen, 2009). However, arguably minimal effort has been directed toward a common and aligned value framework, that is integration beyond project delivery to include management of the whole life cost of the built asset. Integration has become a call for infrastructure (Kumaraswamy, 2011). Full integration involves engagement between design and construction (DC) and operations and management (OM) (cf. Edgar and Teicholz, 2001). We argue a lack of integration between $\mathrm{DC}$ and $\mathrm{OM}$ results in lost opportunities for mobilising synergies and levering value for total asset management (TAM). Bridging these gaps may enhance the ability to deliver sustainable assets through better value identification and project lifecycle cost management. Such development may prove critical given that McKinsey estimate $\$ 57$ trn of infrastructure investment is necessary between now and 2030 to maintain projected global GDP growth (2013).

This paper aims to analyse the extent of integration between DC and OM. The objectives are to examine the concept of integrated solutions as a means to enhance property assets postcompletion. It will examine the extent of the research gap between current DC and OM practice, and hence, identify ways to achieve improvement. Therefore, identifying and highlighting key factors for increased synergy between DC and OM is an important outcome from this under-researched area. We adopt a coordinated view of asset related business processes across multiple organisations (Edgar 
and Teichols, 2001). This is achieved through applying relationally integrated value networks also known as RIVANS (e.g. Kumaraswamy and Rahman, 2006). Bridging the DC and OM lifecycles through an integrated approach in RIVANS for TAM extends previous work.

We build an argument with reference to management literature. We draw upon systems integration and the delivery of as integrated solutions of complex products and systems (cf. Davies,

2004; Davies et al., 2007). Therefore, the TAM element provides integration from the DC lifecycle into the OM lifecycle as knowledge fed forward and back to facilitate improvement in future DC. Three specific application areas are analysed between: DC and OM value levered in networks, value as integrated inputs, and enhancement synergies. The expectation is to empower optimal continuity and sustainability through integrated delivery and management teams, in essence the co-creation of value between key stakeholders in each stage (cf. Pinto and Covin, 1992). Relational integration between teams link processes and systems together.

We first provide an overview of RIVANS as a concept and achieved milestones from previous studies. Second, we establish the link between RIVANS and TAM. This link is significant in achieving systems integration in DC and OM supply chains. We then discuss the methodological fit, research design, findings, analysis and discussion. Finally, conclusions, recommendations, original contribution and limitations are presented.

\subsection{Literature Review}

\section{$2.1 \quad$ RIVANS}

The RIVANS framework combines a focus on network value, the flow of social economic and environmental value streams, and a relational approach (Anvuur et al., 2011: 105). The framework applies supply chain and knowledge management principles to create value across organisational boundaries to enhance project performance. This line of research, initiated by Kumaraswamy, draws upon systems dynamics, network theory, relational contracting and value optimisation in project teams (Kumaraswamy and Rahman, 2006; see also Rahman et al., 2004)). There are two main elements constituting the RIVANS framework: a common goal orientated focus and team synergy. The 
framework suggests improved value arises from performing in integrated ways, whereby the sum of the whole is bigger than the sum of the parts. This involves "aligning and realigning divergent values and behaviours towards a confluence of consolidated high performance levels in both project and strategic networks" (Anvuur et al., 2011: 103). Thus, synergy diminishes the transactional forces, where short-term financial consideration can compromise value, and strengthens relational bonds that potentially support greater effectiveness.

RIVANS therefore aims to integrate multi-organisational project teams in order to enable effective integrated working. This is turn helps align project goals and value creation in execution and maintenance within supply chains (Anvuur et al., 2011). The framework has emphasised project design and construction during execution within an integrated delivery team. The perspective taken here extends beyond DC to OM and TAM. It therefore includes the broader and elongated network covering project lifecycles to include those involved with asset value post-completion (cf.

Kumaraswamy et al., 2010). RIVANS permits estimating potential for more extensive synergies (Rahman, 2003). Such integration to include those maintaining and managing the asset in use (OM stages) had yet to be fully developed.

\subsection{Relationships and DC-OM Lifecycles}

Levering value to maximise asset value, minimise whole-life cost and improve OM is surrounded by arms-length methods and disjointed DC-OM actions. First, accountability poses conflict between complex objectives and demands for information and knowledge among the project stakeholders, leading to difficulties to "streamline and coordinate these interdependent processes" (Halfawy, 2008: 216). Second, responsiveness poses problems regarding emergent needs during DC and asset lifecycles (Too, 2012). Demonstrating value for money is difficult under demands for accountability where delivery costs dominate value-in-use. OM functions and asset managers understand the asset characteristics of quality, safety, operational durability (cf. Too, 2012). Yet these characteristics may not necessarily inform the design and specification during DC (cf. Kennedy, 2007). Similarly, DC actors do not necessarily configure their inputs to optimise asset management and technical solutions. 
For example, suppliers and government policy has brought forward BIM as a technical solution for integrating value and a means to coordinate the organisational actors. However, BIM does not automatically achieve this and induce "soft landings", unless organisationally underpinned by collaboration and integration (e.g. Bosch et al., 2015; Kassem et al., 2015; Love et al., 2015). As with other IT platforms, the computer hardware and software systems are only as good as the human expertise and systems behind the technology.

Disjuncture between DC and OM results in transactional management during contracts of exchange (MacNeil, 1987). Barriers between organisations involved with the DC and OM arise due the division of functional roles, disciplines and organisational boundaries. To achieve integrated, two elements must be considered: the organisation's internal environment including resources and capabilities (Ma, 2000), and the organisation's external environment, including managing external supply networks to capture and maximise value streams (Dubois and Gadde, 2000). We argue this starts at the front-end of the DC stages with knowledge being fed forward into execution and continues into the project in use from where learning is fed back. Thus, DC and OM are both involved in systems integration; two-way information flows and organisational management (Smyth, 2015).

\subsubsection{Systems Integration: Integrating DC-OM}

There is broad agreement in the literature that infrastructure project management and asset management are services provided through a combination of skills, resources and products. There are differences in specific approaches. Kumaraswamy and his colleagues stress collaboration, whereas Davies and his colleagues stress systems integration (Davies, 2004; Hobday et al., 2005; Davies et al., 2006; Davies et al., 2007). In such approaches the traditional assumptions are that OM services reside "downstream" (Davies, 2004: 734) whereas RIVANS for TAM brings them into "upstream" consideration, thus embedded in DC including procurement processes and delivery systems. This includes the consideration of production (project artefact) and consumption (service experience) to add and lever intangible value to the clients (cf. Grönroos, 1990; Davies, 2004; Pinto and Covin, 1992). The connection between systems integration and RIVANS is twofold. First, systems are not 
only technical and procedural, but individual and organisational behaviour from the DC front-end to OM post-completion. Second, collaboration is an important ingredient of effective inputs to enact the system integrator role.

\subsection{Towards RIVANS for TAM}

Examination of factors of integration in DC and for total asset management or TAM is proposed using RIVANS. Any lack of integration may arise from people occupying different DC and OM roles in different organisations. MacNeil stated transactional contracts theoretically need systems to achieve integration (1985). Collaborative behaviour helps mitigate cost in implementing RIVANS for TAM, that is, to practically integrate DC for the benefit of OM. Danylo says, "those who are responsible for efficiently allocating generally insufficient funds among valid and competing needs" need a more specific methodology, which incorporates inventory capability, asset evaluation, predictive and intervention modules and scenario preparation (1998: 92). The allocation of asset resources further depends on the needs and capabilities of the organisation (Edgar and Teicholz, 2001). It leads to asset management being a holistic practice, commencing at the project front-end. Hence TAM requires $\mathrm{DC}$ to mobilise knowledge and expertise during delivery to facilitate TAM for clients and other stakeholders. Co-location of project teams and standardisation of lump sum work packages are insufficient to effectively manage value creation to achieve sustainable TAM. RIVANS for TAM goes a step further towards channeling the potentially divergent value streams into a confluence of consolidated performance for delivery and operation of built infrastructure assets. The theory development starts with the identification of transcendent value artifacts that are important to enable synergies in DC and OM processes to deliver combined integrated solutions.

Current trends of standardised lump sum work packages fail to identify value criteria at two levels. First, they are frequently insufficient for value optimisation from a client viewpoint where work packages are bundled for ease of management reasons. Second, they are insufficient as the contractors and subcontractors are focused upon execution rather than the purpose of the building the asset; thus overlooking TAM. In RIVANS for TAM, managing and coordinating the value network 
upstream points adding long-term value to the lifecycle of the built asset from inception, through maintenance and operations, to retrofitting, demolition and redevelopment. This requires exploiting aligned relationships to ensure that the whole value network is integrated. Thus, upstream and downstream knowledge flows and interventions between clients and key stakeholders in both DC and OM must be direct and seamless. This is greater than technical specification and content; it is relationship based and behavioural. What is the extent of the theory-practice gap? An empirical examination of the extent of RIVANS for TAM therefore examines the extent of integration using RIVANS during DC and OM:

1. Identifying value and value criteria with a magnified focus upon benefits in use and impact;

2. Common practices, attitudes and goals to cooperation to induce synergies;

3. Collaborative contracting leading to systematic relationship management for value leverage across the relevant stakeholders;

4. Current project procurement and delivery systems and current industry norms.

\subsection{Methods}

The research purpose is to identify factors among practitioners to increase the extent of integration between DC and OM for TAM. The purpose embodies "what" and "why" questions. Quantitative methods are more suited to explain what is going on, and qualitative research to understand why it is occurring. A mixed method approach was therefore employed, using deductive and abductive causality. First, a questionnaire was appropriate to scope the field (cf. Smyth and Morris, 2007). Second, semi-structured interviews were conducted in order to provide depth of analysis and clarify issues concerning integration (or the lack thereof) across the networks and at the DC-OM interface, particularly around role and organisational behaviour. 


\subsection{Questionnaire Survey}

The survey data collection started mid-February and lasted until May 2012. Potential respondents were identified from professional membership directories (e.g. RICS and CIOB) on the basis that these professionals are reflective practitioners (cf. Schon, 1983), who should be at the forefront of effective practice and good performance. One thousand and nineteen (1019) of members of these professional bodies, with chartered status, at least five years of post-chartership experience and contact details were selected and invited to respond to the online survey. Three reminders were sent to non-respondents. A total of 95 people had responded; representing a response rate of $9 \%$, which is not inconsistent with response rates for surveys in the construction engineering and management discipline. After data screening and examination, responses from 42 survey participants with at least five years current experience in DC and/or OM roles were retained and are included in this study. The sample size $(N=42)$, had come from 10 client, 10 consultant, 19 contractor and 3 from, other organisations. This sample comprising $34 \mathrm{DC}$ roles and eight $\mathrm{OM}$ roles is adequate for the statistical analysis (see below) given the scoping nature of this element of the study. Some respondents had some dual DC and OM responsibilities and roles. The extent was minimal, and if anything, bias the findings towards greater integration thus to leading to over-optimistic or positive conclusions. Hence, the lack of integration is arguably underplayed in the findings. The respondents worked in organisations with 7 in 1-2 tier supply chains and 3 in $>3$ tier supply chains.

The questionnaire covered the four primary themes: 1) potential better value/synergies realisable from linking $D C$ and $O M$ value networks with a magnified focus upon benefits in use and impact; 2) DC and OM common practices, attitudes and goals in driving the synergies to achieve better value; 3) stakeholder importance in DC and OM value networks for deriving better value by mobilising/exploiting network synergies; 4) effectiveness of functional, relational, and transactional integration modes for giving proper effect to common DC and OM value taking into account industry norms. The items were posed as questions with 5-point Likert response formats $(1=$ 'strongly disagree' to $5=$ 'strongly agree'), except those relating to the most appropriate integration mode, 
which were scored by frequency of mention. 'Better value' was defined in the questionnaire as "better overall project whole-life value for all stakeholders" and 'synergy' as implying all parts working together is greater than the sum of its parts. Functional integration indicates mutual coordination and merged activities, relational integration indicates inter-organisational collaboration achieved through cooperative relationships built on shared goals and values, and transactional integration indicates governance through formal means such as joint ventures.

The data was analysed by examining descriptive statistics and interrater reliability and consensus indices, organised by network type (i.e. DC and OM). The statistics examined were: wholesample frequencies for each integration approach (functional, relational, and transactional); and DC and OM sub-sample means, interrater reliability and interrater agreement indices for ratings of supply chain features, common goals, and stakeholders. Interrater reliability indices assess the relative consistency in ratings provided by multiple judges of multiple targets. In contrast, interrater agreement indices measure the absolute consensus in ratings provided by multiple judges of one or more targets (LeBreton and Senter, 2008). Evidence of satisfactory interrater reliability and interrater agreement is required in this study to use criterion means to draw inferences at the group level (LeBreton and Senter, 2008). The index of interrater reliability used is the two-way random effects average measures intraclass correlation coefficient (ICC), using the "consistency" definition of rating similarity, ICC $(2, K)$. The ICC estimates the proportion of the total variance in respondents' ratings that is due to systematic between-target differences (McGraw and Wong, 1996). ICC (2,K) answers the following questions (LeBreton and Senter, 2008): Are judges' mean ratings stable? Do they reliably distinguish between the groups?

The interrater agreement index used is the James et al. (1984) within-group interrater agreement coefficient, $r_{\text {WG }}$. The $r_{\text {WG }}$ measures the absolute consensus in multiple judges' ratings of a single item. The $r_{W G}$ coefficient can be computed for different null distributions: a rectangular/uniform distribution (for unbiased ratings); triangular distribution (for central tendency bias); and skewed distribution (for leniency/severity bias). Because each criterion factor in this study had an absolute 
value of univariate skewness less than 2 and kurtosis less than 7 , the data were considered to be uniformly distributed following guidelines of Curran et al. (1996: 28).

An inclusive standard for interpreting agreement/reliability coefficients is used (LeBreton and Senter, 2008; Table 3): .00 $\leq$ index $\leq .30$, lack of agreement/reliability; . $31 \leq$ index $\leq .50$, weak agreement//ow reliability; . $51 \leq$ index $\leq .70$, moderate agreement/reliability; $.71 \leq$ index $\leq .90$, strong agreement/high reliability; and $.91 \leq$ index $\leq 1.00$, very strong agreement/very high reliability. Authors (e.g. James et al., 1984) argue that the threshold level of agreement/reliability for a study should be commensurate with the weight of the decision it is used to support. Given the developmental nature of the respondent ratings in this study and in line with the guidelines discussed, the criteria of interest and meriting further consideration are those with agreement/reliability indices of 0.70 or higher.

\subsection{Semi-Structured Interviews}

Semi-structured interviews, employing a qualitative research method, were aimed at soliciting depth and sought to clarify issues concerning integration (or the lack thereof) across the networks and at the DC-OM interface. Interviewees were purposefully selected based upon their expertise and decisionmaking position. The aim was to achieve a balanced range of interviews between DC and OM work roles. Six semi-structured interviews were undertaken. The interviews took place in July 2012 with a range of practitioners representing clients, contractors and consultants from both DC and OM. The transcripts and interview notes were interrogated for patterns and significant issues as corroboration and additional explanation of the quantitative analysis, and depth of understanding of the issues. This was conducted as an iterative process of interrogation and analysis to establish confident interpretation and evaluation of the information. 


\subsection{Findings}

\subsection{Survey Results}

Table 1 shows DC and OM sub-sample means for respondents' ratings of the potential for better value/synergies from linking ten specific features of DC and OM supply chains, and the corresponding $r_{\text {WG }}$ interrater agreement coefficients. Table 1 also shows respondents' assessments of the suitability of functional, relational and transactional integration modes for each of the ten supply chain features. Table 2 shows DC and OM sub-sample means for respondents' ratings of the importance of a set of 11 common goals in promoting synergies/better value, as well as the corresponding $r_{\text {WG }}$ within-group interrater agreement coefficients. Table 3 shows the DC and OM sub-sample means for respondents' ratings of the importance of 12 key stakeholder groupings in DC and OM value networks.

As the results in Table 1 show, the ICC for ratings of the 10 value criteria in Table 1 by the DC sub-sample exceeded the .70 threshold value $[I C C=.72, F=3.624, p=.000]$, indicating strong reliability of the mean ratings by respondents. There was strong to very strong interrater agreement in the DC sub-sample on five value criteria $\left(r_{\mathrm{WG}} \geq .72\right)$. These were: sharing of relevant information and performance data; integrated lifecycle optimisation options/opportunities; overlapping DC-OM supply chain networks; shared/lined resource pools and requirements; and integrated business continuity management opportunities. Interrater agreement coefficients for an information-sharing approach to sustainability issues $\left(r_{\mathrm{WG}}=.70\right)$, and integrated team-building activities $\left(r_{\mathrm{WG}}=.69\right)$ were borderline satisfactory. The sub-sample means for the seven factors are representative of the collective, and show that respondents generally either agree or strongly agree on those factors being important value criteria (means $\geq 3.62$ ). However, the interrater agreement coefficients for the use of similar procurement protocols $\left(r_{\mathrm{WG}}=.55\right)$, expanded long-term business opportunities $\left(r_{\mathrm{WG}}=.61\right)$, and joint use of ICT tools and systems $\left(r_{W G}=.45\right)$ were below the threshold value of .70 , suggesting a lack of satisfactory consensus on the potential contribution of these factors. 
Table 1. Potential better value/synergies from linking, and the best integration type for achieving, DC and OM supply chain features

\begin{tabular}{|c|c|c|c|c|c|c|c|c|c|}
\hline \multirow[b]{3}{*}{ Supply chain feature/attribute } & \multicolumn{6}{|c|}{ Influence on 'better value'/synergies } & \multirow{2}{*}{\multicolumn{3}{|c|}{$\begin{array}{l}\text { Suitability of integration type (by frequency } \\
\text { of mention) }\end{array}$}} \\
\hline & \multicolumn{3}{|c|}{ Mean } & \multicolumn{3}{|c|}{$r_{\mathrm{WG}}$} & & & \\
\hline & $\mathrm{DC}$ & OM & $\begin{array}{l}\text { Whole } \\
\text { sample }\end{array}$ & $\mathrm{DC}$ & $\mathrm{OM}$ & $\begin{array}{l}\text { Whole } \\
\text { sample }\end{array}$ & Functional & Relational & Transactional \\
\hline $\begin{array}{l}\text { Sharing relevant information and } \\
\text { performance data }\end{array}$ & 4.44 & 4.38 & 4.43 & 0.84 & 0.87 & 0.92 & 3 & 19 & 20 \\
\hline $\begin{array}{l}\text { Effective responses to sustainability issues } \\
\text { through information sharing }\end{array}$ & 4.00 & 4.13 & 4.02 & 0.70 & 0.51 & 0.75 & 7 & 17 & 18 \\
\hline Similar procurement protocols & 3.62 & 4.13 & 3.71 & 0.55 & 0.79 & 0.80 & 12 & 15 & 15 \\
\hline $\begin{array}{l}\text { Integrated lifecycle optimization } \\
\text { options/opportunities }\end{array}$ & 4.33 & 4.00 & 4.27 & 0.73 & 0.86 & 0.88 & 10 & 14 & 16 \\
\hline $\begin{array}{l}\text { Overlapping DC and OM supply chain } \\
\text { networks }\end{array}$ & 3.74 & 4.25 & 3.83 & 0.72 & 0.89 & 0.89 & 7 & 23 & 12 \\
\hline $\begin{array}{l}\text { Arranging for shared/linked resource pools } \\
\text { and requirements }\end{array}$ & 3.74 & 4.13 & 3.81 & 0.72 & 0.94 & 0.91 & 12 & 12 & 18 \\
\hline Expanded long term business opportunities & 4.00 & 4.00 & 4.00 & 0.61 & 0.57 & 0.74 & 14 & 18 & 9 \\
\hline $\begin{array}{l}\text { Integrated team-building (human resource } \\
\text { capacity improvement) activities }\end{array}$ & 4.00 & 4.29 & 4.05 & 0.69 & 0.71 & 0.82 & 6 & 15 & 20 \\
\hline Joint use of ICT tools and systems & 3.74 & 3.88 & 3.76 & 0.45 & 0.79 & 0.77 & 9 & 9 & 24 \\
\hline $\begin{array}{l}\text { Integrated 'business continuity } \\
\text { management' opportunities }\end{array}$ & 3.62 & 4.13 & 3.71 & 0.73 & 0.94 & 0.91 & 10 & 17 & 14 \\
\hline$I C C$ & .72 & .62 & & & & & & & \\
\hline$F$ & 3.624 & 2.654 & & & & & & & \\
\hline$p$-value & .000 & .025 & & & & & & & \\
\hline
\end{tabular}

Note: $r_{\mathrm{WG}}$ entries under $\mathrm{DC}$ and $\mathrm{OM}$ are the respective within-group interrater agreement coefficients for the criterion ratings of respondents based on the uniform null distribution, with variance $\sigma_{E U}^{2}=2.0$, for a 5 -point Likert scale ( $1=$ "Strongly disagree" to $5=$ "Strongly agree"). 
In contrast, in the OM sub-sample, there was strong or very strong interrater agreement on all but two value criteria in Table $2\left(r_{\mathrm{WG}} \geq .71\right)$. The two criteria with less than satisfactory interrater agreement coefficients were an information-sharing approach to sustainability issues $\left(r_{\mathrm{WG}}=.51\right)$, and expanded longterm business opportunities $\left(r_{\mathrm{WG}}=.57\right)$. However, the mean ratings in the OM sub-sample demonstrated only moderate reliability [ICC $=.62, F=2.654, p=.025]$. Table 1 also shows the results from whole-sample assessments of the suitability of functional, relational and transactional integration modes for each of the ten value criteria. They show that, generally, relationally integrated team working is the believed to be appropriate. However, transactional approaches are still dominant in areas such integrated team-building, long-term capabilities and joint use of ICT tools, where the emphasis is on integration.

Table 2. Importance of common goals in promoting synergies relevant for achieving better value

\begin{tabular}{|c|c|c|c|c|c|c|}
\hline \multirow[b]{2}{*}{ Common goal } & \multicolumn{3}{|c|}{ Mean } & \multicolumn{3}{|c|}{$r_{\mathrm{WG}}$} \\
\hline & DC & $\mathrm{OM}$ & $\begin{array}{l}\text { Whole } \\
\text { sample }\end{array}$ & DC & OM & $\begin{array}{l}\text { Whole } \\
\text { sample }\end{array}$ \\
\hline $\begin{array}{l}\text { Common project goals such as cost, quality, time, } \\
\text { safety }\end{array}$ & 4.74 & 4.75 & 4.74 & 0.69 & 0.89 & 0.88 \\
\hline Effective and efficient information sharing & 4.50 & 4.75 & 4.55 & 0.66 & 0.89 & 0.87 \\
\hline $\begin{array}{l}\text { Lifecycle oriented project drivers, including overall } \\
\text { sustainability concerns }\end{array}$ & 3.91 & 4.25 & 3.98 & 0.59 & 0.89 & 0.85 \\
\hline $\begin{array}{l}\text { Lifecycle oriented project outcomes, including life } \\
\text { cycle benefit-cost profiles }\end{array}$ & 3.94 & 4.25 & 4.00 & 0.61 & 0.89 & 0.86 \\
\hline Efficient resource utilization and management & 4.15 & 4.25 & 4.17 & 0.60 & 0.75 & 0.81 \\
\hline Expanded business opportunities & 3.82 & 4.00 & 3.86 & 0.56 & 0.86 & 0.83 \\
\hline Long-term network building & 3.94 & 4.50 & 4.05 & 0.60 & 0.86 & 0.84 \\
\hline Relationship building and management & 4.27 & 4.57 & 4.33 & 0.65 & 0.86 & 0.86 \\
\hline Dispute minimization, management and resolution & 4.18 & 4.63 & 4.26 & 0.71 & 0.87 & 0.88 \\
\hline Organisational capacity building & 3.56 & 4.25 & 3.69 & 0.57 & 0.75 & 0.80 \\
\hline Shared corporate social responsibility & 3.64 & 4.00 & 3.71 & 0.35 & 0.71 & 0.69 \\
\hline ICC & .90 & .39 & & & & \\
\hline$F$ & 10.247 & 1.641 & & & & \\
\hline$p$-value & .000 & .166 & & & & \\
\hline
\end{tabular}

Note: $r_{\mathrm{WG}}$ entries under DC or OM are the respective within-group interrater agreement coefficients for the criterion ratings of respondents based on a uniform null distribution, with variance $\sigma_{E U}^{2}=2.0$, for a 5-point Likert scale $(1=$ "Not at all important" to 5 = "Very important").

The means and $r_{\mathrm{WG}}$ values by work type for respondents' ratings concerning the importance of 11 commonly cited supply chain goals are shown in Table 2. For the DC sub-sample, the two-way random 
effects average measures ICC for ratings furnished easily exceeded the .70 threshold value $[I C C=.90, F=$ $10.247, p=.000]$, indicating very high interrater reliability. However, satisfactory interrater agreement was achieved for only two of the 11 common goals. These were project management efficiency (i.e. time, cost, quality, safety), which was only borderline satisfactory $\left(r_{\mathrm{WG}}=.69\right.$; mean $\left.=4.74\right)$, and dispute minimisation, management and resolution $\left(r_{\mathrm{WG}}=.71\right.$; mean $\left.=4.18\right)$. This suggests a business-as-usual focus by the DC sub-sample on just getting the job done. In contrast, for the OM sub-sample, the interrater reliability coefficient $[I C C=.39, F=1.641, p=.166]$ was far below the threshold value of .70 required for satisfactory interrater reliability; this was despite there being strong or very strong interrater agreement in ratings of each common goal $\left(r_{W G} \geq .71\right)$. Thus, the conditions required to justify the use and interpretation of the criterion mean as being indicative of the collective opinion (i.e. ICC $\geq .70$ and $r_{W G} \geq .70$ ) were unmet for the OM subsample.

The results in Table 3 show that there was high interrater reliability in ratings of the importance to a $\mathrm{DC}$ value network of the 12 stakeholder categories in both in the $\mathrm{DC}[I C C=.86, F=7.272, p=.000]$ and OM $[I C C=.84, F=6.342, p=.000]$ sub-samples. For the DC sub-sample, there was satisfactory interrater agreement for only the NGO stakeholder category $\left(r_{\mathrm{WG}}=.70\right)$, and the consensus was that NGOs are only of moderate importance (mean $=2.97)$; this finding was consistent with that for the OM sub-sample $\left(r_{\mathrm{WG}}\right.$ $=.79$, mean $=2.88$ ). For the OM sub-sample, there was also satisfactory consensus (i.e. $r_{\mathrm{WG}} \geq .69$ ) that project constructors, consultants and financiers were moderately important or important (i.e. mean $\geq 3.43$ ) to the DC value network. For ratings of the importance to an OM value network of the 12 stakeholder categories in Table 3, there was high interrater reliability for the $D C$ sub-sample $[I C C=.76, F=4.150, p$ $=.000]$ but satisfactory interrater agreement, if borderline $\left(r_{\mathrm{WG}}=.69\right)$, for main contractors only. Thus, main contractors were viewed by the DC sub-sample as being important stakeholders in an OM value network $($ mean $=4.14)$. Although the OM respondents showed satisfactory interrater agreement for eight stakeholder categories, the interrater reliability coefficient for their ratings was, yet again, substantially lower than the threshold value of $.70[/ C C=.43, F=1.739, p=.141]$. 
Table 3. Importance of key stakeholders in DC and OM value networks

\begin{tabular}{|c|c|c|c|c|c|c|c|c|c|c|c|c|}
\hline \multirow[b]{3}{*}{ Key stakeholders } & \multicolumn{6}{|c|}{ DC value networks } & \multicolumn{6}{|c|}{ OM value networks } \\
\hline & \multicolumn{3}{|c|}{ Mean } & \multicolumn{3}{|c|}{$r_{\mathrm{WG}}$} & \multicolumn{3}{|c|}{ Mean } & \multicolumn{3}{|c|}{$r_{\mathrm{WG}}$} \\
\hline & DC & OM & $\begin{array}{l}\text { Whole } \\
\text { sample }\end{array}$ & DC & $\mathrm{OM}$ & $\begin{array}{l}\text { Whole } \\
\text { sample }\end{array}$ & $\mathrm{DC}$ & OM & $\begin{array}{l}\text { Whole } \\
\text { sample }\end{array}$ & DC & OM & $\begin{array}{l}\text { Whole } \\
\text { sample }\end{array}$ \\
\hline Clients & 4.09 & 4.25 & 4.12 & 0.41 & 0.46 & 0.61 & 4.20 & 4.71 & 4.30 & 0.53 & 0.88 & 0.83 \\
\hline Main contractors & 4.53 & 4.75 & 4.57 & 0.66 & 0.75 & 0.83 & 4.14 & 4.71 & 4.25 & 0.69 & 0.71 & 0.82 \\
\hline Subcontractors & 4.06 & 3.43 & 3.95 & 0.58 & 0.69 & 0.78 & 3.90 & 3.86 & 3.89 & 0.63 & 0.76 & 0.82 \\
\hline Designers and principal consultants & 4.44 & 4.75 & 4.50 & 0.63 & 0.75 & 0.82 & 4.00 & 4.14 & 4.03 & 0.57 & 0.60 & 0.74 \\
\hline Other (specialist / sub-) consultants & 3.91 & 4.00 & 3.93 & 0.64 & 0.71 & 0.81 & 3.72 & 3.86 & 3.75 & 0.65 & 0.76 & 0.83 \\
\hline Suppliers & 3.68 & 3.25 & 3.60 & 0.58 & 0.46 & 0.69 & 3.62 & 2.86 & 3.47 & 0.59 & 0.43 & 0.68 \\
\hline Users & 3.62 & 3.50 & 3.60 & 0.30 & 0.29 & 0.45 & 3.90 & 3.29 & 3.78 & 0.38 & 0.38 & 0.55 \\
\hline General public & 2.97 & 2.38 & 2.84 & 0.47 & 0.58 & 0.69 & 2.78 & 2.43 & 2.71 & 0.26 & 0.69 & 0.64 \\
\hline Relevant non-governmental organisations & 2.97 & 2.88 & 2.95 & 0.70 & 0.79 & 0.86 & 2.76 & 2.86 & 2.78 & 0.62 & 0.76 & 0.82 \\
\hline Relevant statutory bodies & 3.53 & 3.88 & 3.60 & 0.42 & 0.51 & 0.63 & 3.28 & 4.14 & 3.44 & 0.50 & 0.60 & 0.71 \\
\hline Other relevant government organizations & 3.30 & 3.38 & 3.32 & 0.55 & 0.29 & 0.59 & 3.14 & 3.71 & 3.25 & 0.65 & 0.71 & 0.81 \\
\hline Project financiers & 3.91 & 4.5 & 4.02 & 0.38 & 0.71 & 0.71 & 3.59 & 4.71 & 3.81 & 0.55 & 0.88 & 0.84 \\
\hline ICC & .86 & .84 & & & & & .76 & .43 & & & & \\
\hline$F$ & 7.272 & 6.342 & & & & & 4.150 & 1.739 & & & & \\
\hline$p$-value & .000 & .000 & & & & & .000 & .141 & & & & \\
\hline
\end{tabular}

Note: $r_{\mathrm{WG}}$ entries under DC or OM are the respective within-group interrater agreement coefficients for the criterion ratings of respondents based on a uniform null distribution, with variance $\sigma_{E U}^{2}=2.0$, for a 5-point Likert scale (1="Not at all important" to $5=$ "Very important"). 
A key finding from the survey results is that better value and synergies arise from the greater integration of activities, approaches, opportunities and resources/information across the whole lifecycle of a project. This supports the theorisation that integrated solutions are complex, derived from technical and social dimensions. However, we later found this to be understood in principle.

\subsection{The Interview Results}

The interviews conducted suggest information sharing for sustainability is grounded more by regulatory compliance than the optimisation of whole life asset value. Systems integration is restrained in practice and largely confined to technical requirements. The interviews confirm the survey result that transactional approaches to systems integration and the provision of (integrated) solutions still predominate.

The interviews further indicate support for relationally integrated team working and building long-term capabilities up to project handover, beyond which resource commitments and discontinuity amongst DC stakeholders become major constraints to value enhancement and integration from the supply network and OM. Interview participants reported a predominant focus of DC on execution and scepticism about the effectiveness of collaborative BIM, especially for post-completion usage. In general, DC and OM personnel have different perspectives on integration at their interface. Interviewees suggested DC supply chains were hypothetically perceived to have "feed forward" responsibilities from OM, and OM a "feedback" responsibility from DC, thus both externalise responsibility for collaboration and integration.

DC motivation for collaboration was reported as efficiency to protect project budgets. This emphasis squeezed out effectiveness to add value, especially where benefits are realised posthandover. This means that the DC-OM interfaces are distanced from client TAM value realisation.

Investment was low and without investment in portfolio and programme management it was reported that TAM performs a monitoring and information processing role rather than understanding value realisation and having capability to assess facilities and assets for detailed operations. 


\subsection{Discussion of Findings}

The findings show the importance of a whole life integrated approach to infrastructure. This is not new; indeed, it has been the focus of "continuous improvement" agendas in construction (Smyth, 2010;

Finch and Zhang, 2013). However, in contrast to the policy formulations of these agendas, the findings of the survey show that transactional approaches to systems integration and the provision of (integrated) solutions still predominate. A more transformational hence integrated approach is lacking.

The survey findings show important differences of opinion between the DC and OM subsamples. First, OM respondents showed higher levels of agreement on the importance of and contributors to integration than did DC respondents. Second, OM respondents showed strong agreement and DC respondents showed weak agreement on the perceived benefits of using similar procurement protocols and collaborative ICT tools and BIM. Third, DC respondents showed moderate (and less than satisfactory) agreement on the potential benefits to synergy of adopting a longer-term perspective (vis-à-vis project drivers/outcomes, business opportunities, and network building) in contrast to their OM counterparts who showed higher and satisfactory levels of agreement. Although the interrater reliability of the ratings by OM respondents in Table 2 was less than satisfactory, this survey finding is supported by the interviews conducted.

The interview findings reinforced the survey findings in the differences of opinion between DC and OM. They uncovered further underlying reasons. First, they showed the greater focus on relationships and value in DC. Second, BIM research has largely been conducted from a DC perspective (e.g. Hardin, 2011; Kasprzak and Dubler, 2012; Eadie et al., 2013). BIM posed a current management issue constrained by the dominant transactional approaches. Producer and policy claims about BIM for collaboration and integration remain unsubstantiated (cf. Bosch et al., 2015; Kassem et al., 2015; Love et al., 2015). The research survey findings and respondent comments support the argument on the limitations of BIM. All IT systems need human systems of collaboration and integration to be effective. Third, long-term collaboration is perceived as being motivated more by risk reduction and increases repeat business than mobilising knowledge to increase asset values and 
usefulness for TAM; hence relationships in this context are related to project procurement than OM post-completion.

Fourth, there is broad agreement on the importance of all stakeholders, yet opinion differences exist between DC and OM roles. DC respondents displayed consensus on NGOs being of moderate importance to the DC network and on main contractors being important to the OM network but not for the remaining stakeholders. OM respondents displayed consensus for NGOs, contractors, consultants and financiers being (moderately) important to the DC network.

Fifth and in relation to the OM network, respondents reached consensus on clients and government organisations being important. Although the survey showed satisfactory interrater reliability was not achieved, this point is consistent with previous findings (e.g. Dubler et al., 2010; Bernstein and Pittman, 2004). Taken together with the findings above, a significant lack of integration and common understanding of exists across the DC-OM interface. These findings corroborate a related study by Wong et al. (2014). Previous research has also identified as a concern a lack of support from the corporate centres within supply chain networks (cf. Handfield and Nichols, 2002).

A limitation of this study is the small sample sizes for both the survey and interview components. More extensive quantitative and qualitative analysis would be beneficial. The unsatisfactory interrater reliability for the OM sub-sample in this study is another limitation, which may be an artefact of the small sample size $(n=8)$ or may reflect genuine differences of opinion on the issues considered in this study. Likewise, the observed differences in criterion ratings for the DC and OM sub-samples could be due to the small size of the OM sub-sample. These issues should inform future research. Nonetheless, this study provides key insights into TAM and provides useful pointers for future research.

\subsection{Conclusions}

This research identified key factors around integration between DC and OM. It argued that the delivery and management of a built infrastructure asset in the construction industry is only as good as the ability of DC-OM functions to coordinate responses according to client needs. The research agenda 
and literature review were conducted using the RIVANS lens extending it into the TAM domain. The main contribution from the findings is the scant interest in effective integration between DC and OM. There were nuanced differences between DC and OM, yet the overall picture was unambiguous: the trend being towards less integration short-term and a lack of long-term thinking. This challenges prevailing research around whole life costs, post-occupancy evaluation and the claims made for BIM.

Several recommendations flow for research and practice:

- Further investigation, using both quantitative and qualitative techniques to extend and challenge the research presented;

- Develop theoretically informed normative research to improve industry engagement, and induce greater practice awareness;

- Use sustainability agendas to further collaboration and integration;

- Adopt greater realism in research and practice about the limitations of BIM as a technical toolset to solve management-based problems within and across organisations;

Finally, this paper has attempted to take the first steps in developing a RIVANS for TAM framework to enable key stakeholders in both DC and OM stages to quickly undertake repeatable processes in providing solutions in delivery and maintenance of a built asset. Our contribution to TAM comes from both a relational and systems perspective for integration and two-way knowledge flows to increase team synergies that will lead to better value delivery in a "client-centric environment" (Davies, 2004; Davies et al., 2006).

\section{References}

Anvuur, A.M. Kumaraswamy, M.M. and Mahesh, G. (2011). Building "Relationally Integrated Value Networks" (RIVANS). Engineering, Construction and Architectural Management, Vol.18, pp.102-120. 
Bernstein, P. and Pittman, J. (2004), "Barriers to the adoption of Building Information Modeling in the building industry", Autodesk White Paper, http://www.ideateinc.com/whitepapers/bim/Revit BIM Barriers to the Adoption of BIM in the Building Industry.pdf, accessed $15^{\text {th }}$ May 2014.

Bosch, A., Volker, L. and Koutamanis, A. (2015). BIM in the Operations Stage: Bottlenecks and implications for owners. Built Environment Project and Asset Management, Vol. 5, pp.331-343.

Bresnen, M. (2009). Learning to Co-operate and Co-operating to Learn. In: Construction Supply Chain Management, S. Pryke, eds., Wiley-Blackwell, pp.73-91.

Curran, P.J. West, S.G. and Finch, J.F. (1996). The Robustness of Test Statistics to Nonnormality and specification error in Confirmatory Factor Analysis. Psychological Methods, Vol.1, pp.16-29.

Danylo, N.H. (1998). Asset Management: a Tool for Public Works Officials? Journal of Infrastructure Systems, Vol.4, pp.91-92.

Davies, A. (2004). Moving Base into High-Value Integrated Solutions. Industrial Corporate Change, Vol.13, pp.727-756.

Davies, A. Brady, T. and Hobday, M. (2006). Charting a Path Toward Integrated Solutions. MIT Sloan Management Review, Vol.47, pp.39-48.

Davies, A. Brady, T. and Hobday, M. (2007). Organizing for Solutions: Systems Seller vs. Systems Integrator. Industrial Marketing Management, Vol.36, pp.183-193.

Dubler, C.R., Messner, J. and Anumba, C.J. (2010), "Using lean theory to identify waste associated with information exchanges on a building project", Proceedings Construction Research Congress / ASCE Conference, pp. 708-716.

Dubois, A. and Gadde, L.E. (2000). Supply Strategy and Network Effects - Purchasing Behaviour in the Construction Industry. European Journal of Purchasing \& Supply Management, Vol.6, pp.207-215.

Eadie, R., Browne, M. Odeyinka, H., McKeown, C. and McNiff, S. (2013). BIM implementation throughout the UK construction project lifecycle. Automation in Construction, Vol.36, pp.145151. 
Edgar, A. and Teicholz, E. (2001). Accomplishing Total Asset Management. Proceedings of World Workplace, Vol.1, pp.255-266.

Finch, E. and Zhang, X. (2013). Facilities Management, Yao, R (ed), Design and Management of Sustainable Built Enviornments. Springer-Verlag, London, pp.305-326.

Halfawy, M.R. (2008). Integration of Municipal Infrastructure Asset Management Processes. Journal of Computing in Civil Engineering, Vol.22, pp.216-229.

Handfield, R.B. and Nichols. Jr., E,L. (2002). Supply Chain Redesign: Transforming Supply Chains into Integrated Value Systems. New Jersey: Prentice-Hall.

Hardin, B. (2011), BIM and Construction Management, John Wiley \& Sons, Chichester. Hobday, M. Davies, A. and Prencipe, A. (2005). Systems Integration: a core capability of the modern corporation. Industrial Corporate Change, Vol.14, pp.1109-1143.

James, L.R. Demaree, R.G. and Wolf, G. (1984). Estimating Within-Group Interrater Reliability With and Without Response Bias. Journal of Applied Psychology, Vol.69, pp.85-98.

Kasprzak, C. and Dubler, C. (2012). Aligning BIM with FM. Australasian Journal of Construction Economics and Building, Vol.12, pp.68-77.

Kassem, M., Kelly, G., Dawood, N., Serginson, M. and Lockley, S. (2015). BIM in Facilities Management Applications: a case study of a large university complex. Built Environment Project and Asset Management, Vol. 5, pp.261-277.

Kennedy, J. (2007). Asset Management Council: Model and Definition. Proceedings on ICOMS Asset Management Conference 2007, Asset Management Council, Sydney.

Kumaraswamy, M. (2011). Editorial: integrating "infrastructure project management" with its "built asset management". Built Environment Project and Asset Management, Vol. 1, pp.5-13. 
Kumaraswamy, M.M. Rahman, M.M., Palaneeswaran, E. and Ng, S.T. (2002). Innovative Initiatives in Integrating Construction Supply Chains. Proceedings of $1^{\text {st }}$ International Conference on Construction in the $21^{\text {st }}$ Century, April, Miami.

Kumaraswamy, M., and Rahman, M. (2006). Applying Teamworking Models to Projects. In: The Management of Complex Projects: a relationship approach, S. Pryke and H. Smyth, eds., Wiley-Blackwell, pp.164-186.

Kumaraswamy, M. Anvuur, A. and Mahesh, G. (2008). Contractual Frameworks and Cooperative Relationships. In: Collaborative Relationships in Construction, H. Smyth and S. Pryke, eds., Wiley-Blackwell, pp.78-104.

Kumaraswamy, M.M. Anvuur, A.M and Smyth, H.J. (2010). Pursuing "Relational Integration" and "Overall Value" through "RIVANS". Facilities, Vol.28, pp.673-686.

LeBreton, J.M. and Senter, J.L. (2008). Answers to twenty questions about interrater reliability and interrater agreement. Organizational Research Methods, Vol.11, pp.815-852.

Love, P. E., Matthews, J. and Lockley, S. (2015). BIM for Built Asset Management. Built Environment Project and Asset Management, Vol. 5, http://dx.doi.org/10.1108/BEPAM-12-2014-0062.

Ma, H. (2000). Competitive Advantage and Firm Performance. Competitiveness Review, Vol.10, pp.15-32.

MacNeil, I.R. (1985). Reflections on Relational Contract. Journal of Institutional and Theoretical Economics, 141(4), pp. 541-546.

McGraw, K.O. and Wong, S.P. (1996) Forming inferences about some intraclass correlation coefficients. Psychological Methods, Vol.1, pp.30-46.

McKinsey (2013). Infrastructure Productivity, McKinsey Global Institute, McKinsey \& Company. 
Palaneeswaran, E., Kumaraswamy, M.M., Rahman, M.M. and Ng, S.T. (2003). Curing Congenital Construction Industry Concerns through Relationally Integrated Supply Chains. Building and Environmental Journal, 38(4), pp.571-582.

Rahman, M.M. (2003). Revitalising Construction Project Procurement through Joint Risk Management. PhD Thesis, University of Hong Kong, Hong Kong.

Rahman, M., Kumaraswamy, M., Ng, S., Palaneeswaran, E., Lam, E. and Ugwu, O. (2004). Integrating SMCs into construction value chains. In: Proceedings of the 1st International Conference of World of Construction Project Management, Ryerson University, Toronto, May, pp. 27-28.

Schön, D.A. (1983). The Reflective Practitioner: how professionals think in action, Basic Books, New York.

Smyth, H.J. (2010). Construction industry performance improvement programmes. Construction Management and Economics, Vol. 28, pp. 255-270.

Smyth, H.J. (2015). Relationship Management and the Management of Projects, Routledge, London.

Too, E.G. (2012). Journal of Construction Engineering and Management, Vol.138, pp.885-896.

Wong, K.K.W., Kumaraswamy, M., Mahesh, G. and Ling, F.Y.Y. (2014) Building Integrated Project and Asset Management Teams for Sustainable Built Infrastructure Development. Journal of Facilities Management, Vol. 12, pp. 187-210. 